\title{
ASSESSING VISITORS' WILLINGNESS TO PAY (WTP) FOR CORAL REEF CONSERVATION PROGRAM IN PERHENTIAN ISLAND, TERENGGANU, MALAYSIA
}

\author{
MAHIRAH KAMALUDIN ${ }^{1,2 *}$, NAZATUL FAIZAH HARON ${ }^{3}$, ABDUL RAHIM RIDZUAN $^{4}$ \\ AND A.A AZLINA ${ }^{1}$
}

${ }^{1}$ Faculty of Business, Economics \& Social Development, Universiti Malaysia Terengganu, Malaysia. ${ }^{2}$ Institute Oceanography and Environment, Universiti Malaysia Terengganu, Malaysia. ${ }^{3}$ Faculty of Economics and Management Sciences, Universiti Sultan Zainal Abidin, Malaysia. ${ }^{4}$ Faculty of Management and Business, Universiti Teknologi Mara UiTM Melaka, Malaysia.

*Corresponding author: mahirah.k@umt.edu.my

\begin{abstract}
Coral reefs are perform various vital functions aside from being one of the most diverse ecosystems on earth. The coral reefs provide a habitat for more species per unit area than any other marine environment. Therefore, the conservation of coral reefs should be emphasised in order to reduce the damage of coral reefs which impact global ecosystem. The purpose of this study is to estimate the amount and visitors' Willingness To Pay (WTP) for conservation of coral reefs in Perhentian Island, Terengganu and to ascertain the determinants that influence an individual's willingness to pay for conservation programmes. Marine park fees use to cover the cost of park operation such as maintaining the moorings, enforcing rules, research and more. This study examines the degree of visitors' awareness and importance of coral reef conservation using the Contingent Valuation Method (CVM) to estimate visitors' willingness-to-pay for the conservation of coral reefs on the island as non-market goods. This study uses STATA software to analyse the data and the results demonstrate that visitors valued the reef conservation programs at about RM 4.823 (million?). By devoting in conservation, we can safeguard the environment, and without immediate action and rapid mobilisation of resources, the reefs involve widespread collapse, and may trigger losses in the future.
\end{abstract}

Keywords: Conservation, coral reef, Contingent Valuation Method (CVM), sustainability, Willingness To Pay (WTP).

\section{Introduction}

The need for and importance of the conservation of the natural environment has significant relevance and contributes much to the growth of the economy especially in coastal zones. It is important to have proper environmental planning and management, so that serious conflicts regarding coastal space and resource utilisation and the deterioration of natural resources that interrupts or limits development options can be avoided (Post \& Lundin, 1996).

Many people know that the marine environment in Malaysia is rich in biological diversity, and consists of coral reefs, mudflats, mangroves, seagrasses, lagoons and estuaries. Coral reefs perform vital for various functions, being among the most diverse ecosystems on Earth.

For instance, the coral reefs are able to:

(i) defend seashores from the harmful effects of wave and tropical storm activity,

(ii) offer places and shelter for numerous marine creatures,

(iii) provide nitrogen and crucial nutrients for marine food chains,

(iv) contribute to carbon and nitrogen setting and

(v) assist with nutrient recycling. 
Coral reefs are a habitat for many more species compared to other marine environments, comprising 4,000 species of fish, 800 species of corals and hundreds of other species. ReakaKudla (1997) found that there are probably between 1 and 8 million undiscovered species living in and around coral reefs.

The reefs also offer economic and environmental potential to millions of individuals to the tune of US\$375 billion a year (Costanza et al., 1997). Value of the reefs expanded massively in estimated value from
US\$8,000 to around US\$352,000 per hectare a year following additional studies on erosion protection, storm protection, natural barriers and recreation. The increasing value of the reefs still located outside the market and measured as non-tradable public benefits. The reefs are frequently recognised as rainforests of the sea as there are many benefits they can provide just by the massive total of species they harbour and the natural balance and protection they offer. For instance, Table 1 presents an example of reef's ecosystem service at Veracruz Reef System National Park, Mexico.

Table 1: Ecosystem services of coral reefs

\begin{tabular}{ll}
\hline & Ecosystem Services \\
\hline Regulating & Shoreline protection \\
& Erosion protection \\
\hline Supporting & Habitat \\
& Biodiversity \\
\hline Cultural & Recreation \\
& Research \\
& Environmental education \\
& Aesthetic \\
\hline Provisioning & Hook fishing \\
& Long line fishing \\
& Net fishing \\
\hline
\end{tabular}

Source: Reyna-González et al. (2014)

Besides its function as a nursery for a wide range of species, the coral reefs also provide revenue for fisheries and tourism. Healthy coral reefs promote commercial and existence fisheries industries and other businesses such as tourism and recreation. It was projected that reef recreation value in the Caribbean is about US\$1,654 per hectare per year (Ahmed et al., 2007).

Almost half of world's fisheries rely on the coral reefs in their life cycle. Local economies obtain billions of dollars from visitors through recreational fishing trips, diving tours, hotel bookings, and other businesses operation located near reef habitats. Even with their enormous economic and recreational value, coral reefs are exposed to critical levels of pollution, habitat devastation and disease. Once coral reefs are damaged, they are unable to maintain the organisms that live in the areas in and around the reef. Thus, when reefs support less fish, plant, and marine animal life, it loses its value as a tourist destination too.

Presently, coral reef ecosystems around the world are threatened and may well become extinct. The coral reefs are vulnerable due to human recreational activities, climate change, overfishing and sedimentation. 
Numerous marine conservation programmes have been implemented to help conserve and sustain this precious marine resource. An effective way to safeguard and restore coral reef ecosystems is through implementation of Marine Protected Areas (MPA) as this can limit human activity in and around the reef, which would give the reef time to repair itself and replenish its fish and marine life stocks. If coral reef resources continue to be exhausted without reprieve, not only will it put the livelihoods of the communities in the area that are dependent on the reef at risk, it puts the entire ocean ecosystem in danger too. Conservation and restoration of coral reef habitats is crucial to the future of the nations that are relying on the reef.

\section{Background of Study}

Perhentian Island is a beautiful island which is situated in the state of Terengganu, East Coast of Malaysia. The islands consist of two islands such as Perhentian Besar and Perhentian Kecil. Perhentian Island is situated about 10 nautical miles $(19 \mathrm{~km})$ off the coast of north-eastern Malaysia in the state of Terengganu, and about 40 miles $(64 \mathrm{~km})$ south of the Thai border.
The islands are relatively untouched and the only populations live in a small fishing village in Perhentian Kecil. The islands offer white sandy beaches, spectacular coral reefs, crystal clear waters, a marine park and virgin forests which are famous among tourists, particularly scuba divers.

In 1994, the area around the Perhentian Island was gazetted as a marine park under Malaysian law. The protected waters extends two nautical miles $(3.7 \mathrm{~km})$ from the seashore. Tourists to the Perhentian Islands must pay a Conservation Fee to the Department of Marine Parks Malaysia. The conservation charge is used to finance management of the marine park, which comprises monitoring, conservation, protection, research, education and awareness programmes. The conservation fee is RM5 for adult and RM2 for children between the ages of 6 and 12, individuals aged 56 years and above, and the disabled gain entry for free. For nonMalaysian citizens, pay RM30 for adults, and RM15 for children aged between 6 and 12, and senior citizens (60 years and above). Figure 1 illustrates the map of Perhentian Island which is located in the district of Besut, Terengganu. The island offers many tourist destinations for scuba diving and snorkelling activities.

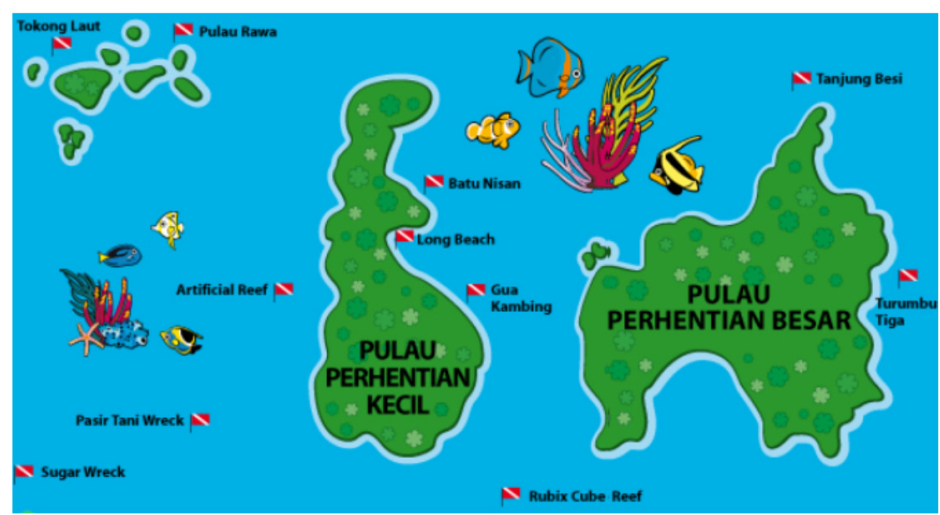

Figure 1: Map of Perhentian Island, Terengganu, Malaysia Source: Malaysiadaytrip, 2020 
However, ecotourism activities on the island pose a negative effect on the marine and coral ecosystem. Researech shows that $90 \%$ of the coral reefs in Perhentian Islands have encountered coral bleaching, which has put large swathes of the reef at risk of death and extinction (Mohamad Saifudin et al., 2014). Recreational activities such as snorkelling, diving, sailing, and underwater photography could harm the ecosystems in the long run especially if it is unregulated. Keller et al. (2009) points out that coral reefs are very fragile and delicate organisms; and the recreational activities mentioned earlier could put the entire ecosystem at risk.

Hence, this study of Willingness To Pay (WTP) for coral reef conservation is required as one of the efforts towards a better management of sustainability in coastal zone area in Perhentian Island.

This paper presents its findings on the estimation of the WTP study among visitors to Pulau Perhentian Marine Park (PPMP). The aim of this study is to observe visitors' preferences and perceptions regarding the economic value offered by coral reefs.

While, a previous study by Akhter and Shzee Yew (2015) focussed on all the marine resources in Perhentian Island. This study focused solely on the coral reefs conservation as it is the most biodiverse ecosystem of the ocean. Understanding visitors' willingness to pay for the conservation is an efficient manner to assess visitors' perception and motivation to estimate visitors' enjoyment. The results of the study can be used as a guideline to create a more sustainable reef-side activities in future.

Unlike the study conducted by Akhter and Shzee Yew (2015), this study considered "attitude" as an extended variable to measure the willingness to pay value. This gives the study an even greater impact on the visitors' perception and makes it an essential measurement tool to investigate their satisfaction level. Ahkter and Shzee Yew (2015) also provided an estimation based on median of visitors' WTP, this study calculated the mean (average) of the WTP. This study also provides valuable information to PPMP to formulate changes to its conservation initiatives particularly with regard to the entrance fee which had been implemented since 2003 .

\section{Literature Review}

The conservation of coral reef is very important as it is a diverse ecosystem with many attractive features and natural resources which are of immense value as resources for production and which offer numerous health benefits for human beings.

Despite this, reefs all over the world are increasingly under threat from factors such as the rapid development of the tourist industry which has expended dramatically and put a strain on the coral reefs and marine ecosystems' ability to recover from the excess of human activity.

According to a study by Zhang, Chung and Qiu (2016) on Mabul Island, Malaysia, between $8 \%$ and $14 \%$ of hard coral damage that occurred to the reef-line on the island increased exponentially with the rise in the number of divers.

Reef Check Malaysia (2018) stated in its report that the conditions of the coral reefs and its impact on the environment had several different repercussions on the local economy. For instance, when the tourist numbers increased, there was a corresponding increase in the impact to the reef.

There is a link to the amount of physical damage to the reef by divers, snorkelers, and boats, triggering further pollution to multiple sources such as sewage and the number of such tourists visiting the reef. Conversely, when the tourist numbers are low, the impact to fish stocks seems to increase, which puts pressure on the already fragile coral reef ecosystem. This situation is compounded by illegal and unscrupulous activities like fish bombing; which is common in the waters off the coast of Sabah.

In view of this, effectively managing coral reefs is critical to guarantee the sustainability of resources and for future generations. 
Coral reefs are an important barometer of ocean health and provide an ocean ecosystem that supports an enormous number of marine animals, rich in biodiversity which has immense value to humankind as a source of natural resources. It also functions as a natural protective barrier to coastal zones reducing the power of the waves during typhoons, hurricanes and storms. It also limits coastal erosion, flooding, and loss of property on the shore, the reefs also save billions of dollars in insurance and reconstruction costs and avoid the need to install expensive coastal defences and barriers.

Previous researchers have found that individuals have significant willingness to pay (WTP) for such conservation efforts depending on the socioeconomic background and travel behaviour of the respondents. The excess WTP values for fishing, diving, and sightseeing visitors was analysed using a random utility model (Lee, Chen \& Chen, 2019).

Another study was done to examine divers' ecological preferences and environmental values to assess their willingness to contribute to watershed management, agencies seek to manage to include water supply, water quality, drainage, stormwater runoff, water rights and the overall planning and utilisation of watersheds.

In the study, divers were willing to voluntarily contribute US\$900 towards watershed-sediment projects that could benefit them by improving reefs' conditions (Grafeld et al., 2016). Meanwhile, Maynard et al. (2019) estimated a visitors' willingness to pay for coral reefs conservation in Kenting National Park, Taiwan. The results suggested that a total value of US\$680 million per year could theoretically be collected for conservation. This study applied a contingent valuation method by using pictures and ecological data which followed systematic procedures although the survey was conducted using an Internet survey for coral reefs valuation.

The valuation on coral reefs delivers a sound economic justification especially for conservation initiatives. The benefit of coral reefs is not just in providing a habitat for a multitude of aquatic species but also acts as a natural protector for coastal cities, communities and beaches. Trujillo et al. (2016) estimated recreational divers' willingness to pay for the conservation of the coral reefs in the Corals of Rosario and San Bernando National Natural Park. This study suggested that divers' willingness to pay for the coral reefs conservation at the park was US\$89.95 per person.

The marine protection strategies and environmental development were crucial. In this sense, the investigation on the probability of paying for marine conservation was conducted in Zhejiang Province, China. The study showed that the amount was mainly influenced by individual disposable income and closely related to the individual awareness level (Yu et al., 2018).

Other studies aimed at understanding visitors' perceptions on environmental quality, preferences for coastal amenities, and willingness to pay for changes in coastal lodging attitudes. Using choice experiment (CE) method, the results indicated that visitors have strong preferences for beach-front lodging and a strong aversion to beach litter (Schuhmann et al., 2016). Getzner, Jungmejer and Spika (2016), discussed the willingness to pay to conserve marine biodiversity with significant outcome that can contribute to the site's longterm financing and management.

Ahmed et al. (2007) noted there are other components that needed to be highlighted; for instance, in the role of advocacy, education and awareness campaigns to improve people's WTP for the management of coral reefs besides focusing on wide range benefits of coral reef itself. The destruction of reef lines and unstable reef management may result in losses to and hamper the economic performance of coastal towns and cities especially when compared to the economic benefits of sustainable healthy reefs (White, Vogt \& Arin, 2000).

Using a Contingent Valuation Method (CVM) to determine WTP can be characterised 
as market based and non-market techniques where include indirect and direct measures. Akhter and Shzee Yew (2015), completed their valuation study out of visitors willingness to pay to protect marine resources at Pulau Perhentian Marine Park (PPMP). They strongly suggest that, an increase in the amount of entrance fees is necessary in order to develop sustainable conservation activities properly. These valuable outcomes will not only benefit park authorities but policymakers by helping them understand how to calculate the aggregate conservation benefit of natural resources against balanced economic growth at PPMP.

\section{Research Methodology}

Contingent Valuation Method (CVM) is employed to determine Willingness To Pay (WTP) value for a single scenario providing combination of quantity and quality of a public good. Following the Exxon Valdez oil spill, a contingent valuation study was conducted a one-time WTP for a scenario involving escaping another large and damaging oil spill was implemented using in-person interviews (Carson et al., 2003). The CVM employed surveys to determine the maximum WTP for a hypothetical market for the environmental good/ service. Then, value of environmental good/ service was estimated through mean WTP times and the affected population. The CVM creates a hypothetical market which is compulsory because of the absence of a real market for the good/service. The hypothetical market created in this manner must be reasonable, logical and acceptable.

\section{Model Specification}

The measure of value used by CVM is based on the Hiksian concepts of equivalent and compensating surplus. Depending on the assignment of rights to the resource in question, respondents are asked about their Willingness To Pay (WTP) to attain an improvement of environmental assets or to evade a decline in supply; or their willingness to accept (WTA) compensation for a decrease in supply or their willingness to pay for the decline in the supply.

The CVM follows the Random Utility Theory (RUT) which accepts individual actions realistically and indicates an alternative with the highest level of utility, i.e. that an individual is engaged in utility-maximisation. The utility $U$ that the individual $i$ gets from the consumption of a good is made up of an observable deterministic component $V$ (the utility function) and a random component $\varepsilon$. Then the individual's utility function will be as follows (Eq. 1);

$$
\mathrm{U}_{\mathrm{ij}}=\mathrm{V}_{\mathrm{ij}}+\varepsilon_{\mathrm{ij}}
$$

$$
\mathrm{V}_{\mathrm{ij}}=\alpha_{\mathrm{ij}}+\beta\left(\mathrm{Bid}_{\mathrm{j}}\right)+\mu \mathrm{Z}_{\mathrm{i}}
$$

Where Z presents the respondents' characteristics. Moreover, mean WTP is calculated based on the formula used by Cameron (1988) as follows;

$$
\mathrm{WTP}=\alpha / \beta\left(\mathrm{Bid}_{\mathrm{i}}\right)
$$

This study applies a dichotomous choice referendum WTP question design in its contingent valuation survey as below:

"If there is an implementation to increase
entrance fee to Pulau Perhentian Marine
Park for an increment in conservation
charges towards better management in
coral reefs would you votes in favour?
Yes or No?"

$\log ($ Probability Yes/ (1-Probability Yes $))=\beta_{0}-$ $\beta_{1}($ Bid $)+\beta_{2} X_{2}+\beta_{3} X_{3}$

Where \$Bid is the amount of price levels that asked to the respondents, Xs are the values of the non-price bid independent variables that denotes tastes and preferences towards the resource of interest. The estimation of Contingent Valuation Method (CVM) employed in this paper followed Hanemann (1984). It is 
worth noting that the visitors' willingness to pay for reef conservation activities can be influenced by the following;

Prob $\{$ Yes $\}=\operatorname{Prob}\left\{\mathrm{WTP}_{\text {max }}>\right.$ Price bid $\} ; 1$ (favour)

Prob $\{\mathrm{No}\}=$ Prob $\left\{\mathrm{WTP}_{\max }<\right.$ Price bid $\} ; 0$ (against)

Where, Price bid is the offered price bid for conservation charge, $\mathrm{WTP}_{\max }$ is maximum Willingness To Pay (WTP). This study applies Cumulative Distribution Function (CDF) to model regression because the response variable is dichotomous, by noting 0 - 1 values (Gujarati \& Porter, 2009).

The equations (5) and (6) designate that if the offered price bid (BID) amount is more than individual's maximum willingness to pay, then they are not willing to pay to place for that amount. Though, if the bid is lower than their maximum willingness to pay amount, the chance of responding to that amount is "yes", it presents they will maximize utility and are willing to place value for that precise amount.

These equations response on random utility context is regarding on consumer decision making about the conservation program of coral reefs.

\section{Results}

\section{Survey Implementation}

This study applies referendum or discrete choice of CVM to assess visitors' willingness to pay towards reef conservation in Perhentian Island, Terengganu. Structured interviews and willingness to pay surveys were implemented with visitors and with fishing villages on Perhentian Island in order to assess visitor's willingness to pay of coral reef conservation.

Actual surveys were conducted among visitors to Pulau Perhentian Marine Parks with 114 respondents selected randomly. The survey was implemented via face-to-face interviews and structured questionnaires regarding visitor's willingness to pay.

The survey questionnaire comprises information on the socio-economic characteristics of respondents including; gender, age, household income and education level attained. The findings regarding the characteristics of the respondents based on their socio economic background is shown in Table 2 as follows:

Table 2: Respondents' characteristics based on socio-economic background

\begin{tabular}{lccc}
\hline \multicolumn{1}{c}{ Characteristics } & Frequency & Percentage & Mean \\
\hline Male & \multicolumn{2}{c}{ Gender } & \\
Female & 64 & 56.1 & \\
\hline \multicolumn{5}{c}{ Age (years) } & 43.9 & \\
\hline $18-25$ & 56 & 49.1 & 33.17 \\
$26-35$ & 27 & 23.7 & \\
$36-45$ & 21 & 18.4 & \\
$46-55$ & 7 & 6.1 & \\
$56-80$ & 3 & 2.6 & \\
\hline & Marital status & & \\
\hline Single & 64 & 56.1 & \\
Married & 49 & 43.0 & \\
Divorce & 1 & 0.9 & \\
\hline
\end{tabular}




\begin{tabular}{lcc}
\hline & \multicolumn{2}{c}{ Education level } \\
\hline Primary school & 0 & 0 \\
Secondary school & 42 & 36.8 \\
Diploma & 50 & 43.9 \\
Bachelor Degree & 21 & 18.4 \\
Master/PhD & 1 & 0.9 \\
\hline & \multicolumn{2}{c}{ Job status } \\
\hline Government & 26 & 22.8 \\
Private & 24 & 21.2 \\
Business & 39 & 34.2 \\
Retired & 1 & 0.9 \\
Student & 24 & 21.1 \\
\hline & \multicolumn{2}{|c}{ Income (RM) } \\
\hline RM 0 - 500 & 24 & 21.1 \\
RM 501 - 1500 & 22 & 19.3 \\
RM 1501 - 2500 & 35 & 30.7 \\
RM 2501 - 3500 & 20 & 17.5 \\
RM 3501 - 4500 & 7 & 6.1 \\
RM 4501 - 5500 & 3 & 2.6 \\
RM 5501 - 6500 & 2 & 1.8 \\
RM 6501 - 7500 & 1 & 0.9 \\
\hline
\end{tabular}

Table 2 denotes the characteristics of the 114 being; 33 years. As expected, most respondents visitors to Perhentian Island Marine Park who (56.1\%) were single; visitors who came to visit took part in this study. Most of the respondents marine park with friends. About $43.9 \%$ were were men with the average age of the respondents diploma holders and with an average income of RM2,026.32 a month.

Table 3: Reasons for respondents to be willing to pay for coral reef conservation

\begin{tabular}{lcc}
\hline \multicolumn{1}{c}{ Reasons } & Frequency & Percentage \\
\hline It is my responsibility to conserve coral reefs & 84 & 70.9 \\
It is my actions to support our government's effort & 25 & 24.3 \\
I can afford to contribute for conservation & 5 & 4.8 \\
\hline Total & 114 & 100 \\
\hline
\end{tabular}

Table 3 breaks down the respondents' responses as to why they voted for coral reefs conservation in the island. Most of the respondents $(70.9 \%)$ stated that it was their responsibility to conserve marine natural resources and this shows a high awareness of coral reef conservation among the visitors.
About 25 of respondents (24.3\%) pointed out that they were willing to increase the conservation charges to support government's effort to conduct conservation activities. Meanwhile, five respondents $(4.9 \%)$ mentioned they can afford to pay for the increment in the conservation charge towards coral conservation programmes. 
Table 4: Respondents' reasons against coral conservation programs

\begin{tabular}{lcc}
\hline \multicolumn{1}{c}{ Reasons } & Frequency & Percentage \\
\hline I have other commitments rather than to allocate spending on conservation & 72 & 49.8 \\
I am not confident with the management of trust fund & 42 & 29.1 \\
I do not feel the need to allocate spending for conservation & 21 & 14.2 \\
I am not willing to pay for the proposed price bid & 10 & 6.9 \\
\hline Total & 145 & 100 \\
\hline
\end{tabular}

Table 4 presents respondents' reasons against an increment in conservation charges at Pulau Perhentian. About 49.8\% said that they have other commitments in expenses. While, $29.1 \%$ were not confident with management of Trust Fund that runs the programmes. Another $14.2 \%$ of respondents also stated that current conditions are still acceptable, and there was no immediate need for any conservation activity.
Overall, of the respondents involved in final survey, 10 stated they were not willing to pay for the proposed bid, saying that if the proposed bid was lower, they might vote for the programme.

A total of 31 respondents were omitted from the survey as they objected the idea of coral reef conservation programmes. Therefore, only 114 respondents were involved in the data estimation.

Table 5: Respondents' perceptions towards the importance of coral reef conservation

\begin{tabular}{|c|c|c|}
\hline Variables & Description & Mean \\
\hline $\begin{array}{l}\text { Attitude } 1 \\
\text { (use value) }\end{array}$ & Coral reefs contribute significantly in tourism sector in Terengganu. & 4.35 \\
\hline $\begin{array}{l}\text { Attitude } 2 \\
\text { (non-use value) }\end{array}$ & Coral reefs are important as it has the highest biodiversity of ecosystems & 4.43 \\
\hline $\begin{array}{l}\text { Attitude } 3 \\
\text { (bequest value) }\end{array}$ & It is important to have coral reefs for future generations & 4.41 \\
\hline $\begin{array}{l}\text { Attitude } 4 \\
\text { (existence value) }\end{array}$ & $\begin{array}{l}\text { Coral reefs are often called the rainforests of the sea, both due to the vast } \\
\text { amount of species they harbour, and to the high productivity they yield }\end{array}$ & 4.16 \\
\hline Attitude 5 & $\begin{array}{l}\text { Good management of marine parks are important for conserving the } \\
\text { coral reefs }\end{array}$ & 4.38 \\
\hline Attitude 6 & $\begin{array}{l}\text { Coral reef conservation programmes are able to create income and } \\
\text { job opportunities to local communities }\end{array}$ & 4.24 \\
\hline
\end{tabular}

Referring to the use value attribute, most respondents believed that the coral reefs significant to tourism sector in the state. Beautiful coral reefs can attract many visitors to Perhentian Island. The dependency of the travel and tourism sector on healthy reefs goes much deeper than that as the reef not only offers entertainment value but can deflect large waves that exacerbate shore erosion.
For Attribute 2, the respondents stated that they were aware that coral reefs have the highest biodiversity among all natural ecosystems. The ecosystem is made up not only of hard and soft corals, but also includes fish, jelly fish, sharks and many more.

The health, abundance and variety of the organisms that make up a coral reef are directly connected to the close marine environments. For bequest value via Attribute 3, the 
respondents understand the importance of coral reefs for future generations. Managing coral reef resources for future generations is vital. As the reefs are important for the biodiversity and the services they provide such as coastal protection, jobs, food and recreational opportunities.

Attribute 4 demonstrates existence value as the respondents realise that the importance of coral reefs to environment. Vigorous and healthy coral reefs offer many benefits since the reefs support an extraordinarily biodiverse range of marine life and are home to several different types of fish, invertebrates and sea mammals.

\section{Regression Analysis}

The outcomes from the CVM studies were regressed by using Logit Model and carried out by econometric software STATA11. The dependent variable is Willingness To Pay (WTP) and the independent variables were estimated such as bid price, income, age and importance of coral reefs for future generation.

$W T P_{i}=\boldsymbol{\beta}_{0}+\boldsymbol{\beta}_{1}$ price bid $+\boldsymbol{\beta}_{2}$ income $+\boldsymbol{\beta}_{3}$ age + $\boldsymbol{\beta}_{4}$ importance of reefs $+\boldsymbol{\varepsilon}$

It is predicted that the WTP to be positively correlated with income, age and importance of reefs for future generations. Though, price bid presents a negative relationship, as the offered price increases for conservation charges, the WTP among visitors decreases in line with the demand theory (Mohd Rusli, Alias \& Ahmad, 2009).

Table 6: The estimated parameters of single bounded CVM (Final Regression)

\begin{tabular}{|c|c|c|c|c|}
\hline Variables & Coefficient & $\begin{array}{l}\text { Standard } \\
\text { Deviation }\end{array}$ & Wald & Significance \\
\hline Price bid & $-1.127 * * *$ & 0.253 & 19.862 & 0.000 \\
\hline Tourist's income & $0.001 * * *$ & 0.0001 & 10.974 & 0.001 \\
\hline Age & 0.042 & 0.032 & 1.753 & 0.186 \\
\hline Supporting importance of reefs & $1.995 * *$ & 1.103 & 3.269 & 0.071 \\
\hline Constant & 0.643 & 1.471 & 0.191 & 0.662 \\
\hline
\end{tabular}

Note: $(* *) 5 \%$ level, $(* * *) 1 \%$ level

The results of Logit model show price bid and income are highly significant at $1 \%$ level. The variable of "importance of reefs for future generation" depicts a positive and significant relationship at $10 \%$ level. The sign of variables in Logit Model is similar as expected in Equation (7).

The negative sign in price bid is same in previous studies as Akhter (2015) and Mohd Parid (2010), higher offered price bid of conservation charge will lower visitors' WTP. Income, age and perception on importance of coral reefs for future generations shows positive signs as it shows possibility of a "yes" answer increases with a visitors' income, age and perception.

Respondents who supported coral reef conservation were also willing to allocate funds for conservation programme. The respondents realised the significance of reefs that are more than just the most diverse ecosystems on the planet.

The reefs are able to protect coastlines from the damaging effects of large waves, tropical storms and provide habitats and shelter for many marine creatures. 
Table 7: Estimated minimum, maximum and mean of visitors' willingness to pay in Perhentian Island

\begin{tabular}{ccccc}
\hline & $\mathbf{N}$ & Minimum & Maximum & Mean \\
\hline Estimated WTP & 114 & 3.01 & 10.04 & 4.8230 \\
\hline
\end{tabular}

Table 7 shows estimated willingness to pay in Perhentian Island for coral reef conservation charge. The minimum amount demonstrates RM3.01, maximum amount is stated at RM10.04 and mean (average) visitors' WTP is RM4.82. Respondents were in favour of any conservation activities or programmes towards coral reefs in the island for the sake of its survival.

\section{Conclusion}

The purpose of the study was to apply the CVM on coral reef conservations for amenity, biodiversity and other values in Perhentian Island, Terengganuto estimate the WTP that will be used to conserve coral reefs. It is beneficial to protect and conserve the marine resources and ensure tourism growth in Perhentian Island.

The proposed entrance fee could support and implemented proper conservation activities. The determinants of price bid, income, age, and perception on knowledge on coral reefs contribute significantly to the WTP among visitors.

This study recommends RM4.82 as an entrance fee with a conservation charge on top of current entrance fee to Marine Park.

Coral reef conservation benefits can be monetised with the aim of identifying its economic and demographic characteristics and factors.

Millions of human beings count on the reefs for food and to make a living. Reefs also form naturally sheltered lagoons and protect coastlines and mangroves against wave damage. Currently, coral reefs are under threat from global warming, pollution and direct human harm, by way of unethical overfishing among other things.

Coral reefs are very productive ecosystems and are a vital component of ocean health. They not only support ocean biodiversity, they are of value to humankind.

Thus, to address local needs for management of marine resources, NGOs and government agencies should implemented a selection of low cost and effective programmes that can be recognized as "soft interventions". These soft interventions emphasise enforcement, education, public relation activities, monitoring and volunteer programmes.

Following more detail examples, the role of many parties such as local governments and NGOs, which are located nearest to the Island should be enhanced through a partnership with the local people of Perhentian Island. They can implement a special project that can encourage local people to recognize and report conservation priorities in the island and give a reward to them. Besides, by providing more education, training and awareness to local people, so that they are very alert about possible changes that might occur in the conservation area to increase awareness level among them.

Coral reef conservation efforts are aligned with the Sustainable Development Goal (SDG) 14: Life Below Water which focuses on sustainably managing and protecting the marine and ecosystems from pollution. The SDG 14 also addresses the impacts of ocean acidification.

These interventions require funding in order to enhance the intensity of the implementation. In observing the requirements for adaptation to play a role in establishing a more sustainable future for reefs, it is imperative to consider the consequences of future climate changes too.

Sustainability in tourism development can be achieved if the country is serious abot protecting its natural resources and ocean heritage by emphasising all possible impacts including the impacts of future climate changes on earth. 


\section{Acknowledgements}

This work was not funded by any grants, but we appreciate anonymous reviewers for their careful reading of our manuscript and their insightful comments and suggestions. Authors received no financial support for the research, authorship, and/or publication of this article.

\section{References}

Ahmed, M., Umali, M. G., Chong, K. C., Rull. F. M., \& Garcia, C. M. (2007). Valuing recreational and conservation benefits of coral reefs - The case of Bolinao, Philippines, Ocean \& Coastal Management, 50, 103-118.

Akhter, S., \& Shzee, Y. T. (2015). Tourists' willingness to pay for marine resource conservation at Pulau Perhentian Marine Park, Malaysia, Greener Journal of Economics and Accountancy, 4(2), 029041.

Cameron, T.A. (1988). A new paradigm for valuing non-market goods using referendum data: Maximum likelihood estimation by censored logistic regression. Journal of Environmental Economics and Management, 25, 355-379.

Carson, R. T., Mitchell, R. C., Hanemann, W. M., Kopp, R. J., Presser, S., \& Ruud, P. A. (2003). Contingent Valuation and Lost Passive Use: Damages from the Exxon Valdez, Environmental and Resource Economics, 25, 257-286.

Costanza, R., dArge, R., de Groot, R., Farber, S., Grasso, M., Hannon, B., Limburg, K., Naeem, S., Oneill, R.V., Paruelo, J., Raskin, R.G., Sutton, P., \& van den Belt, M. (1997). The value of the World's Ecosystem Services and Natural Capital. Nature, 387, 253-260.

Getzner, M., Jungmeier, M., \& Špika, M. (2016). Willingness-To-Pay for improving marine biodiversity: A case study of Lastovo Archipelago Marine Park (Croatia). Water, 9(1), 2.
Grafeld, S., Oleson, K., Barnes, M., Peng, M., Chan, C., \& Weijerman, M. (2016). Divers' willingness to pay for improved coral reef conditions in Guam: An untapped source of funding for management and conservation? Ecological Economics, 128, 202-213.

Gujarati, D. N., \& Porter, C. D. (2009). Essentials of Econometrics (4th ed.). New York, USA: McGrawHill.

Hanemann, W. M. (1984). Welfare evaluations in Chontingent Valuation Experiments with discrete responses, American Journal of Agricultural Economics, 66(3), 332-341.

Keller, B. D., Gleason, D. F., McLeod, E., Woodley, C. M., Airame, S., Causey, B. D., Friedlander, A. M., \& Steneck, R. S. (2009). Climate change, coral reef ecosystems, and management options for marine protected areas. Environmental Management, 44(6), 1069-1088.

Lee, C. H., Chen, Y. J., \& Chen, C. W. (2019). Assessment of the economic value of ecological conservation of the kenting coral reef. Sustainability, 11(20), 5869.

Malaysiadaytrip. (2020). Perhentian Island Travel Map. http://malaysiadaytrip.com/ perhentian-island-travel-guide.html

Maynard, N., Château, P.-A., Ribas-Deulofeu, L., \& Liou, J.-L. (2019). Using internet surveys to estimate visitors' willingness to pay for coral reef conservation in the Kenting National Park, Taiwan. Water, 11(7), 1411.

Mohamad, S. M. S., \& Nik, N. N. H. (2014). Ecotourism and coral reef: Analysis of Coral Reef Conservation Awareness among stakeholders in Perhentian Island, Malaysia, American Journal of Tourism Management, 3(1A), 7-12.

Mohd, P. M. (2010). Economic valuation of the nature tourism area of Pulau Redang Marine Park, Terengganu, Malaysia. (Master's Thesis). Universiti Putra Malaysia.

Mohd, R., Alias, R., \& Ahmad, S. (2009). A Contingent Valuation Study of Marine 
Parks Ecotourism: The case of Pulau Payar and Pulau Redang in Malaysia. Journal of Sustainable Development, 2(2), 95-105.

Post, J. C., \& Lundin, C. G. (Eds.). (1996). Guidelines for integrated coastal zone management. The World Bank.

Reaka-Kudla, M. L. (1997). The global biodiversity of coral reefs: A comparison with rainforests. In Reaka-Kudla, M. L., D. E. Wilson, \& E. O. Wilson (Eds.), Biodiversity II: Understanding and protecting our natural resources, (pp. 83108). Washington, D. C.: Joseph Henry/ National Academy Press.

Reef Check Malaysia. (2018). Status of coral reefs in Malaysia, 2017. Reef Check, Malaysia.

Reyna-González, Pedro, Bello-Pineda, Javier, Ortiz-Lozano, L., Pérez España, Horacio, Arceo, Patricia \& Brenner, Jorge. (2014). Incorporating expert knowledge for development spatial modeling in assessing ecosystem services provided by coral reefs: A tool for decision-making. Revista De Biología Marina Y Oceanografía, 49, 279292.
Schuhmann, P. W., Bass, B. E., Casey, J. F., \& Gill, D. A. (2016). Visitor preferences and willingness to pay for coastal attributes in Barbados. Ocean \& Coastal Management, 134, 240-250.

Trujillo, J. C., Carrillo, B., Charris, C. A., \& Velilla, R. A. (2016). Coral reefs under threat in a Caribbean marine protected area: Assessing divers' willingness to pay toward conservation. Marine Policy, 68, 146-154.

White, T. A., Vogt, P. H., \& Arin. T. (2000). Philippine coral reefs under threat: The economic losses caused by reef destruction. Marine Pollution Bulletin, 40(7), 598-605.

Yu, B., Cai, Y., Jin, L., \& Du, B. (2018). Effects on willingness to pay for marine conservation: Evidence from Zhejiang Province, China. Sustainability, 10(7), 2298.

Zhang, L. Y., Chung, S., \& Qiu, J. (2016). Ecological carrying capacity assessment of diving site: A case study of Mabul Island, Malaysia. Journal of Environmental Management, 183, 253-259. 
